\title{
Selection of Poplar Hybrid Clones (Populus ssp.) from Backcrossed Progenies of the Aigeiros Section for Industrial Purpose
}

\author{
By GuAnG-HuA QIN ${ }^{1)}$, Yue-Zhong JiAnG ${ }^{\left.1),{ }^{*}\right)}$ and YU-Ling QIAO ${ }^{1)}$
}

(Received 31 ${ }^{\text {th }}$ May 2012)

\begin{abstract}
As one of the fast-growing tree species, hybrid poplar (Populus ssp.) has been widely planted in Shandong Province, China. While poplar tree breeding program in the past few decades focused on the development of poplar clones with fast growth rate and disease resistance, little attention was paid to the tree traits of these clones in relation to industrial uses i.e. pulpwood as well as veneer. In this paper, growth performance of hybrid poplar clones from backcrossedprogenies obtained from cross fertilization within the Poplar Aigeiros Section was evaluated and stem traits as well as wood properties in relation to industrial use of some selected clones were assessed. Of the 40 hybrid poplar clones tested in the study, A50 and B69 were prominent in growth rate at three trial sites in Shandong Province, China.Wood properties in relation to industrial uses of the two clones were also better than or comparable to the control clone. It was concluded that A50 is more suitable for pulpwood production while B69 is suitable for a wide range of high value added application such as veneer and plywood. Further research is needed to evaluate the changes of some tree traits in relation to industrial raw materials through time.
\end{abstract}

Key words: Populus, Aigeiros, controlled pollination, growth rate, stem traits, wood property, veneer, pulpwood.

\section{Introduction}

Poplars (Populus ssp.) have been planted in China since very early times (HEILMAN, 1999) and have been the primary timber producer in regions lacking of natural forests like Shandong Province in China. The area of land planted to poplar in China reached more than 7 million hectares in 2007 due to the increasing demand for wood and the release of fast-growing and diseaseresistant hybrid poplars from breeding programs supported by both international and national organizations. Although still a minor supplier of timber in the world, poplar plantations made great contributions totimber supply in China. More attention has been paid to poplar plantation since the implementation of Natural Forests Protection Program in China in 1998 to seek alternative sources of raw materials as the natural forests are protected and managed for environmental services such as recreation, conservation, watershed protection, and carbon sequestration rather than for wood products. As a fast-growing tree species, poplar enhances the possibili-

\footnotetext{
1) Shandong Forestry Academy, No. 42 Wenhuadonglu, 250014 Jinan, Shandong, China.

*) Corresponding author: Yue-ZHong JIANG.

Telephone: +86-531-88557771, Fax: +86-531-88932824. E-Mail: guanghuaqin@163.com
}

ty to cover increasing wood demands (LIEVEN et al., 2007). However, the shift of end use of poplar wood from rafters, posts and beams in construction (FAO, 1980) to industrial uses such as plywood and pulpwood in recent days has triggered interests and development of new hybrid poplar varieties (clones) for industrial use. Hybrid poplar wood has proven to have some desirable characteristics for many nonstructural timber and fiber products. Planted area of hybrid poplar for pulpwood and plywood has increased in floodplain area like Shandong Province in Eastern China since 2000s. Benefited from various poplar breeding programs, a large number of hybrid poplars have been introduced to Shandong since the 1980s. These hybrid poplars, primarily intended for nonstructural purpose, have been paid little attention to stem characteristics and wood properties as required by veneers. More attention should be paid to stem traits and branch characteristics if poplar wood is to be used for veneer or sawtimber. For that purpose, poplar clones with cylindrical, straight, non-crooked and high taper stem; small branches and flat branching habits; high density and low shrinkage wood, are preferred (ADRIAN, 2002). Moreover, pulpwood related properties such as pulp yield, fiber morphology and hand sheet properties etc. should be studied in detail if poplar trees are to be used for that purpose.

The genus Populus is divided into five sections, and three sections, Aigeiros, Leuce, and Tachamahaca, are the most important from the standpoint of poplar cultivation (FAO, 1980). Aigeiros, represented by two species, European blackpoplar (P. nigra L.) and eastern cottonwood ( $P$. deltoides Bartr.), which together with their large number of hybrids (commonly known as $P . \times$ canadensis or $P . \times$ euramericana), makes up over $90 \%$ of all cultivated poplars of the world (HEILMAN, 1999). Poplar clonesof the Aigeiros Section are also important in Shandong Province considering the fact that poplar accounts for more than $80 \%$ planted area in the region.

Many previous studies have proven that significant differences could be found in growth traits among clones of the Aigeiros Section (RAJORAET al., 1994; QIN et al., 2003). Other studies indicated that some wood properties, such as density and dimensional shrinkage,tend to display clone-to-clone variations (STEENACKERSET et al., 1996; LIEvEn et al., 2007). This provides a sound basis for the inter-and-intra-specific hybridization among the species and clones within the Aigeiros Section and the selection of clones with desirable tree traits required by veneer and pulpwood from backcrossedprogenies.

This paper presents the results of a 12-year poplar breeding program started in 1998 in Shandong 
Province, China to select hybrid poplar clones for veneer and pulpwood from backcrossedprogenies obtained from cross pollination within the Aigeiros Section by considering their growth rates, stem traits, wood physical and pulping properties. We hypothesized that differences exist in tree traits like growth rate, stem traits, wood properties etc. among clones of backcrossedprogenies obtained from hybridization within the Aigeiros Section.

The objectives of this paper are: (1) to identify the variation in growth rates, stem traits, wood and pulping properties among the clones tested; (2) to determine promising hybrid poplar clones for industrial use by considering a number of tree traits including growth rates, stem traits, and other end-use related wood properties such as wood density, dimensional stability, chemical composition, pulping properties etc. as required by veneer or pulpwood in the riparian area in Shandong Province.

\section{Materials and Methods}

\section{Mating design and controlled pollination}

Controlled cross breeding method was applied by following a test cross design (Table 1). Three male poplar clones PE-3-71 (P. deltoides cv. 'PE-3-71'), PE-19-66 (P. deltoides cv. 'PE-19-66') and S307-26 (P. deltoides cv. 'S307-26'), introduced to China from Turkey in later 1980s (QIN et al., 2003), were used to cross with two female poplar clones I-69 (P. deltoides cv. 'Lux I-69/55') and I-72 (P. $\times$ euramericana cv. 'San Martino I-72/58') to produce six full-sibling backcrossed progenies. In winter 1998, floral cuttings (3-5 cm in diameter and 0.5-1.0 m in length) of each parent were placed in pots for rooting by accessing to aerated water at the bottom in a greenhouse at Shandong Forestry Academy. Water in the pot was replaced every 2 days to keep fresh. Air temperature in the greenhouse was kept around $20-25^{\circ} \mathrm{C}$ and relative air humidity to be $50-70 \%$. Three to fivesets of female inflorescencesof each cutting were maintained and others were removed to reserve enough nutrients for seed development at later stage while all the male flowers were kept in each cutting to collect as much pollen as needed for pollination. Each cross combination was isolated from other combinations to prevent open pollination. Female flowers were pollinated by hand, using a small brush with pollen of the male parent.

\section{Early selection and seedling test in the nursery}

Catkins developed on well-rooted female cuttings after pollination. It took about 25-30 days for capsulesto reach maturation and seedstoshed, depending on female clones. All cross combinations, except for I-72 $\times$ PE-1966 and I-72 $\times$ S307-26, produced some seeds, more or less, to conduct further tests. Mature seeds of each cross combination were collected and sown in soil in the greenhouse and then out planted in the nursery. There were altogether 1200 seedlings that survived after one growing season in winter 1999 and height of each seedling was recorded (Table 2). Large variation in growth rate was observed among individual seedlings and such variation, mainly caused by genetics, made possible the selection of superior individuals from the backcrossed progeny population (RIEMENSCHNEIDER et al., 1994). In total, 123 superior seedlings, 60 from I-72 $\times$ PE-3-71, 26 from I-69 $\times$ PE-3-71, 22 from I-69 $\times$ PE-19-66 and 15 from I-69 $\times$ S307-26 with height greater thanthe mean height of seedlings were primarily selected and clonally propagated in the following two years (2000 and 2001) to conduct seedling test (Table 2).

In early April, 2002, 1-year-old shoots of the 123 selected clones from 4 cross combinations, were cut into 12-18 cmlong cuttings and planted by hand at $80 \times 30 \mathrm{~cm}$ spacing following a randomized complete

Table 1. - Mating design.

\begin{tabular}{lccc}
\hline Parentage & $P E-3-71(6)$ & P'E-19-66(6) & $\$ 307-26(6)$ \\
\hline $1-72(9)$ & A & - & - \\
$I-69(9)$ & B & $C$ & D \\
\hline
\end{tabular}

Table 2. - Number of seedlings per combination surviving after one growing season, number of clones selected for the seedling test, and number of clones selected for multi-clonal comparative test in the field.

\begin{tabular}{lccc}
\hline $1-72 \times$ PE-3-71 & 625 & $60(\mathrm{Al}-\mathrm{A} 60)$ & 14 \\
$1-72 \times \mathrm{PE}-19-66$ & 0 & 0 & 0 \\
$1-72 \times \mathrm{S} 307-26$ & 0 & 0 & 0 \\
$1-69 \times \mathrm{PE}-3-71$ & 232 & $26(\mathrm{~B} 61-\mathrm{B} 86)$ & 9 \\
$\mathrm{I}-69 \times \mathrm{PE}-19-66$ & 220 & $22(\mathrm{C} 87-\mathrm{C} 108)$ & 5 \\
$\mathrm{I}-69 \times \mathrm{S} 307-26$ & 123 & $15(\mathrm{D} 109-\mathrm{D} 123)$ & 8 \\
Tolal & 1200 & 123 & 36 \\
Mean height $(\mathrm{m})$ & 1.76 & 2.13 & 3.20 \\
\hline
\end{tabular}


block design with 20 cuttings per block and 3 replicates to conduct seedling test at Meng-li Nursery, Chang-qing District. There were altogether 7440 cuttings (including one control clone I-107 as check) planted, and the trial was surrounded with 2 rows of I-107 cuttings.Normal tending measures were taken to raise the seedlings, i.e. timely weeding to eliminate the competition of weeds for soil water and nutrition, andproper irrigation to maintain soil moisture. Height and collar diameter of each tree were recorded after one growing season. As variation in collar diameter was less than that in height, height was the prime variable based on which the superior seedlings were selected. Thirtysixclones with height growth statistically higher than or equal to control clone I-107were selected for multi-clonal comparative test in the field (Table 2).

\section{Multi-clonal comparative test in the field}

\section{Study area}

Located in the north hemisphere temperate zone, Shandong has a warm, temperate climate, with an annual average of $750 \mathrm{~mm}$ of rainfall and a mean temperature of $13^{\circ} \mathrm{C}$. Most rainfall occurs from June to August, which synchronizes with the growth peak of poplar.Three trial sites in Shandong, Gao-qiao (Lat. $35^{\circ} 45^{\prime} 47^{\prime \prime N}$; Lon. $116^{\circ} 48^{\prime} 00^{\prime \prime} \mathrm{E}$; Alt. $59 \mathrm{~m}$ ) at Ning-yang County,Meng-li (Lat. 36 $33^{\prime} 40^{\prime \prime N}$; Lon. 116 $44^{\prime} 42^{\prime \prime} \mathrm{E}$; Alt. $45 \mathrm{~m}$ ) at Chang-qing District, and Zhao-wang (Lat. $36^{\circ} 50^{\prime} 33^{\prime \prime} \mathrm{N}$; Lon. $120^{\circ} 42^{\prime} 49^{\prime \prime} \mathrm{E}$; Alt. $71 \mathrm{~m}$ ) at Lai-yang City, with light loam or loam soil type, representative of poplar planted area, were selected for the multi-clonal comparative test in the field (Fig. 1). Trialsincluded 36 clones, 26 in common to three sites, from four cross com- binations, together with I-107, L35, 2025 and I-69, all widely employed in establishing poplar plantation in the region and included in the trial as checks. All the trials at three sites were following a randomized complete block design, despite some differences in tree numbers and area planted (Table 3). The plantations were established using 1-year-old seedlings with roughly the same collar-diameter. Each trial plantation was bordered by two rows of control clone I-107 to eliminate border effect. Some differences e.g. soil condition, planting spacing, and tree numbers planted among the three trials, could possibly influence the results. However, such differences do not preclude the comparative analysis among clones tested within a givensite (O'NeIL et al., 2010).

\section{Traitsmeasurement and statistical analysis}

$\mathrm{DBH}$ (diameter at breast height of $1.3 \mathrm{~m}$ ) and HT (height) of each tree were recorded yearly beginning in the fall-winter of 2003 until 2010. Considering the fact that branch accounts for small proportion of tree volume, stem volume (VOL) outside bark without branches, rather than tree volume, was used to analyze the comparative growth rate of clones tested, and it was calculated using equation 1 as follows:

$$
V O L=\pi \times(D B H)^{2} \times H T / 100(1)
$$

Where $V O L=$ stem volume outside bark without branches in $\mathrm{dm}^{3} \cdot$ tree $^{-1} ; \pi=3.14 ; \mathrm{DBH}=$ diameter at breast height in $\mathrm{cm} ; H T=$ height in $\mathrm{m}$; assuming all the trees in the trial had same form factors at breast height $\left(f_{1.3}=0.4\right)$. Mean values of DBH, HT and VOL in each block were used in statistical analysis.

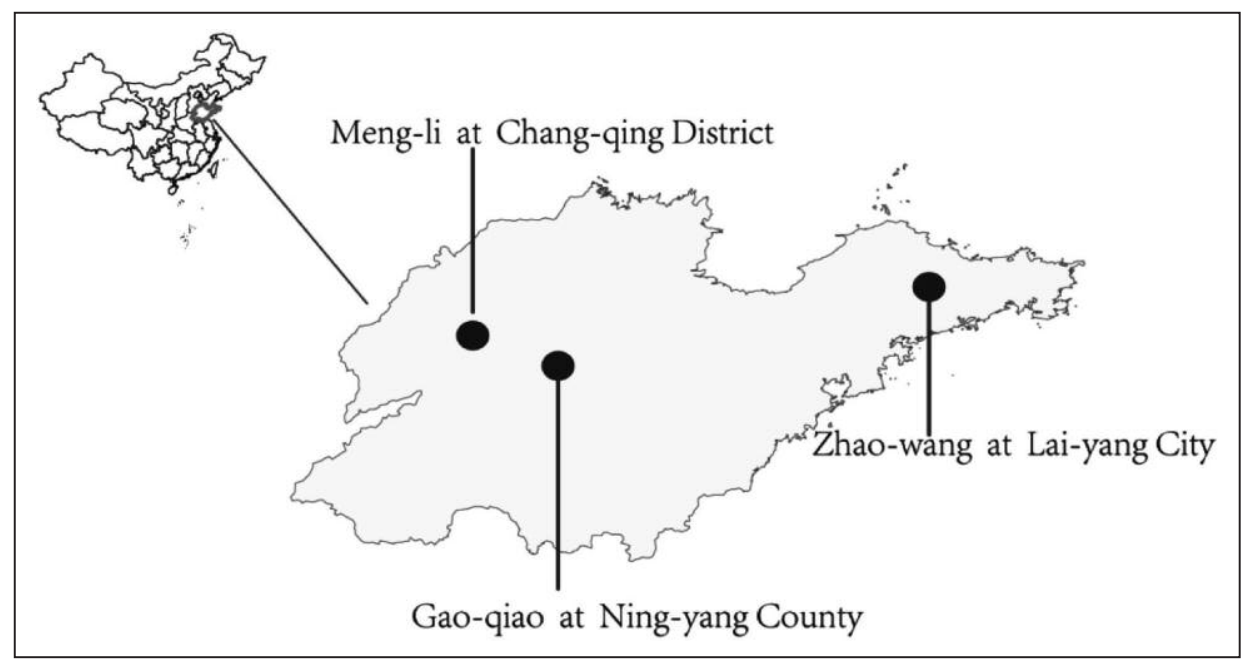

Figure 1. - Location of test sites in Shandong Province.

Table 3. - Randomized complete block design for trial plantation at three sites.

\begin{tabular}{llccccc}
\hline Site & $\begin{array}{l}\text { Establishing } \\
\text { ycar }\end{array}$ & $\begin{array}{l}\text { \# of clones } \\
\text { tested }\end{array}$ & Plot shape & $\begin{array}{l}\text { \# of trees in } \\
\text { cach plot }\end{array}$ & Spacing Replicates \\
\hline Gio-qiao & Spring 2003 & 30 & 3 rows across $\times 4$ trees deep & 12 & $4 \times 4 \mathrm{~m}$ & 3 \\
Meng-li & Spring 2005 & 40 & 3 rows across $\times 3$ trees deep & 9 & $4 \times 3 \mathrm{~m}$ & 3 \\
7hao-wang & Spring 2005 & 40 & 3 rows across $\times 3$ trees deep & 9 & $4 \times 3 \mathrm{~m}$ & 3 \\
\hline
\end{tabular}




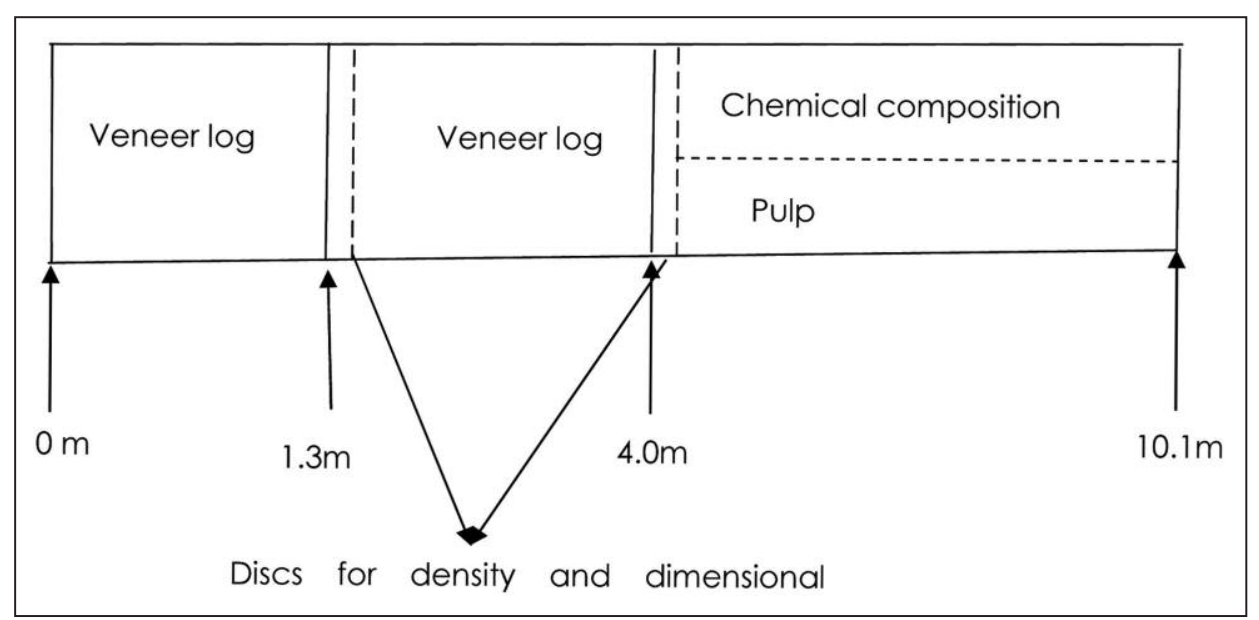

Figure 2. - Partitioning of trees in relation to the different specimen required for test.

In 2010 at Gao-qiao site, trees of selected clones were visually examined and valued for stem traits and branching characteristics based on the description for scoring different tree traits by ADRIAN (2002) with onsite observation. Briefly, the scoring is described as follows: Roundness of the stem: $0=$ cylindrical, $1=$ nearly cylindrical, 2 =ellipsoidal; Crookedness: 0 = straight stem, 1 = with one crook, $2=$ with two crooks; Taper: HT/DBH; Forking: 0 = no forks, 1 = single fork, 2 = multiple forks; Branch diameter at the joint to the bole: $0=<2 \mathrm{~cm}, 1=2-4 \mathrm{~cm}, 2=>4 \mathrm{~cm}$ (trait measured for five largest branches from the main branch layer); Branch angle: trait measured for five randomly selected branches in each tree.

Three trees, with mean DBH of each preliminarily selected clone at Gao-qiao site, together with check clones, I-107 and 2025, were cut in 2008 at the age of 6 for end-use related wood property determination. Trees were sawn into stem discs, logs and beams, depending on the different tests to be performed, according to the scheme shown in Fig. 2.

For evaluating specific gravity and the shrinkage upon drying of the wood, stem discs of $10 \mathrm{~cm}$ thick were taken at $1.3 \mathrm{~m}$ and $4.0 \mathrm{~m}$ (Fig. 2). Specimen for accessing specific gravity, radial shrinkage, tangential shrinkage, volumetric shrinkage were prepared according to national standards for testing wood properties (GB/T1927-194391). Values were volume weighted average.

Of each stem, two logs of $1.3 \mathrm{~m}$ (from 0 to $1.3 \mathrm{~m}$ ) and $2.6 \mathrm{~m}$ (from 1.4 to $4.0 \mathrm{~m}$ ) respectively, were peeled using industrial equipment to evaluate veneer quality (loss by clipping i.e. holes and cracks and sheet shrinkage) and then subsequently plywood properties (glue bond strength). The thickness of the veneer was $1.7 \mathrm{~mm}$. Clipping losses were related to the edge trimming and defect elimination. As poplar veneer was mostly used for interior application in making plywood, darkening of veneer caused by heartwood coloration was not considered in this study. 3-layer-plywood was produced out of the veneers peeled using a urea-formaldehyde glue. These boards were tested for glue bond strength according to national standards (GB/T 14074.10-1993).

Of each stem, samples for measuring fiber morphology and for testing wood chemical composition and pulp properties were taken from 4.1 to $10.1 \mathrm{~m}$ (Fig. 2). For the pulping tests, APMP process was applied under the conditions as follows: $6.3 \% \mathrm{NaOH}$ (sodium hydroxide), $6.0 \% \mathrm{H}_{2} \mathrm{O}_{2}$ (hydrogen peroxide), $168^{\circ} \mathrm{C}$, and $120 \mathrm{~min}-$ utes. Stems were chipped and refined using an atmospheric $30 \mathrm{~cm}$-diameter refiner. Tappi standard test methods were applied for hand sheet tests.

Statistical analysis was carried out using the ANOVA procedures in SAS (SAS INSTITUTE, 1999). Least significant differences were determined at the 0.05 level.

\section{Results and Discussion}

\section{Growth rate at three trial sites}

Considering the differences in planting spacing and soil conditions etc. among the three sites, it is meaningless to statistically compare the growth rate among the sites. Results of clones tested within each given site, however, showed that some clones, common to three sites, had significantly faster growing rates than others, while some clones appeared to be poorly suited to the three sites across the Province. Some clones, performed well in one or two site (s) but poor in other site (s). Since the three sites are representative of poplarplanted area in the region, it is possible to identify some clones that performed well and could be used in the poplar plantation establishment.

While the rank of the clones in growth rate might change through the life of the trial, previous studies showed that there were large age-age correlation for DBH, HT and VOLof poplar (FOSTER, 1988; ADRIAN, 2002). This makes early selection of poplar clones possible. Since the calculation of VOLis based on variables of both $\mathrm{DBH}$ and HT, we will consider VOL, rather than $\mathrm{DBH}$ and HT, as the prime variable of interest and use it for comparison analysis. 
At Gao-qiao site, significant differences in VOL could be found among the clones tests (Table 4). A50 and B69, with a VOL of $392.1 \mathrm{dm}^{3} \cdot$ tree $^{-1}$ and $390.7 \mathrm{dm}^{3} \cdot$ tree $^{-1}$ respectively, were significantly higher $(18.0 \%$ and $17.6 \%$ more) than control clone I-107 with a VOL of $332.1 \mathrm{dm}^{3}$.tree ${ }^{-1}$. Not significantly different from control clone I-107were D117 (345.9 dm $\mathrm{dm}^{3}$.tree $\left.{ }^{-1}\right)$, B63 (337.8 $\mathrm{dm}^{3}$. tree $\left.^{-1}\right)$, L35 (333.0 $\mathrm{dm}^{3}$. tree $\left.^{-1}\right)$, and A12 $\left(332.6 \mathrm{dm}^{3}\right.$.tree $\left.{ }^{-1}\right)$. All the clones had a VOL above the mean growth $\left(285.3 \mathrm{dm}^{3}\right.$.tree $\left.{ }^{-1}\right)$ of the clone group tested. Several clones, B74, C102, I-69, D113 and A35, with VOL of $230.1 \mathrm{dm}^{3}$. tree $^{-1}, 219.6 \mathrm{dm}^{3}$. tree $^{-1}$,
$218.7 \mathrm{dm}^{3}$.tree ${ }^{-1}$ and $197.3 \mathrm{dm}^{3}$.tree ${ }^{-1}$ and 181.7 $\mathrm{dm}^{3}$.tree ${ }^{-1}$ respectively, had VOL below the mean growth $\left(285.3 \mathrm{dm}^{3}\right.$.tree $\left.{ }^{-1}\right)$, showing poor adaptation at Gao-qiao site.

At Meng-li site, significant differences in VOL existed among the clones tests (Table 5). A50, B69, C103 and D120 were significantly higher in VOL growth than control clone I-107. A50, with a VOL of $236.4 \mathrm{dm}^{3} \cdot$ tree $^{-1}$ (26.7\% higher than control clone I-107), was the leader in the group. Next to A50, clones of B69, C103, and D120 were $25.0 \%, 16.5 \%, 14.5 \%$ higher in VOL growth than control clone I-107. Not significantly different

Table 4. - DBH, HT and VOL of 30 hybrid poplar clones grown from 2003 to 2010 at Gao-qiao, Ning-yang County.

\begin{tabular}{|c|c|c|c|c|c|}
\hline Clone & DBIL $(\mathrm{cm})$ & $\mathrm{IIT}(\mathrm{m})$ & VOL $\left(\mathrm{dm}^{3} \cdot \operatorname{tree}^{-1}\right)$ & $\begin{array}{l}\text { VOI comparcd to } \\
\mathrm{I}-107(\%)\end{array}$ & Ranking \\
\hline A 50 & 23.5 & 22.6 & $392.1^{\text {it }}$ & 118.0 & 1 \\
\hline B69 & 23.2 & 23.1 & $390.7^{\mathrm{a}}$ & 117.6 & 2 \\
\hline D 117 & 22.7 & 21.4 & $345.9^{\mathrm{l}}$ & 104.1 & 3 \\
\hline B 63 & 22.2 & 21.8 & $337.8^{1 \mathrm{kc}}$ & 101.7 & 4 \\
\hline L35 & 22.1 & 21.7 & $333.0^{1 \mathrm{bc}}$ & 100.2 & 5 \\
\hline $\mathrm{A} 12$ & 22.6 & 20.8 & $332.6^{1 \mathrm{x}}$ & 100.1 & 6 \\
\hline I- 107 & 22.2 & 21.4 & $332.1^{\text {lxed }}$ & 100.0 & 7 \\
\hline $\mathrm{C} 108$ & 22.5 & 20.8 & $330.4^{\text {ladk }}$ & 99.4 & 8 \\
\hline$B 85$ & 22.3 & 20.9 & $324.9^{\mathrm{ked}}$ & 97.8 & 9 \\
\hline A 118 & 22.4 & 20.6 & $323,7^{\text {lecde }}$ & 97.4 & 10 \\
\hline 690 & 22.4 & 20.4 & $321.1^{\text {bedc }}$ & 96.6 & 11 \\
\hline 2025 & 22.3 & 20.2 & $316.0^{\mathrm{led}=}$ & 95.1 & 12 \\
\hline $\mathrm{A} 9$ & 21.9 & 20.5 & $309.5 \mathrm{cst}$ & 93.1 & 13 \\
\hline $\mathrm{C} 103$ & 21.4 & 20.7 & $299.1^{\text {detge }}$ & 90.0 & 14 \\
\hline$A 17$ & 21.5 & 20.4 & 297.2 & 89.4 & 15 \\
\hline A49 & 21.1 & 19.9 & 279.6 & 84.2 & 16 \\
\hline$D 120$ & 20.9 & 19.7 & 270.3 & 81.4 & 17 \\
\hline$B 78$ & 21.0 & 19.4 & 268.3 & 80.7 & 18 \\
\hline$A 8$ & 20.4 & 19.1 & 251.2 & 75.6 & 19 \\
\hline D)122 & 20.5 & 19.0 & 250.4 & 75.4 & 20 \\
\hline $\mathrm{A} 18$ & 20.4 & 19.0 & 247.5 & 74.5 & 21 \\
\hline$[0110$ & 20.2 & 18.9 & 241.4 & 72.6 & 22 \\
\hline A 16 & 20.2 & 18.8 & 240.4 & 72.4 & 23 \\
\hline B 365 & 20.1 & 18.8 & 239.0 & 71.9 & 24 \\
\hline A 51 & 20.1 & 18.7 & 237.4 & 71.4 & 25 \\
\hline$B 74$ & 19.9 & 18.5 & 230.1 & 69.2 & 26 \\
\hline$C 102$ & 19.5 & 18.3 & 219.6 & 66.1 & 27 \\
\hline $1-69$ & 19.6 & 18.1 & 218.7 & 65.8 & 28 \\
\hline D113 & 18.8 & 17.8 & 197.3 & 59.4 & 29 \\
\hline A35 & 18.1 & 17.6 & 181.7 & 54.7 & 30 \\
\hline Meals & 21.2 & 20.0 & 285.3 & & \\
\hline $\mathrm{P}$ & $<10^{3}$ & $<10^{3}$ & $<10^{3}$ & & \\
\hline$C V(\%)$ & 3.2 & 1.8 & 7.1 & & \\
\hline $\operatorname{LSD}_{0,0}$ & 1.1 & 0.6 & 33.3 & & \\
\hline
\end{tabular}

* Only clones with VOLs statistically higher than or equal to control clone I-107 are labeled. 
from control clone I-107were B63, L35, and C108, with VOL growth of $197.4 \mathrm{dm}^{3} \cdot$ tree $^{-1}, 195.6 \mathrm{dm}^{3} \cdot$ tree $^{-1}$ and $190.0 \mathrm{dm}^{3}$.tree ${ }^{-1}$ respectively. All the clones had a VOL above the mean growth $\left(160.6 \mathrm{dm}^{3}\right.$.tree $\left.{ }^{-1}\right)$ of the clone group tested. Several clones, C96, A26, A35, A9 and D115, with VOL of $113.1 \mathrm{dm}^{3} \cdot$ tree $^{-1}, 111.5 \mathrm{dm}^{3} \cdot$ tree $^{-1}$, $104.6 \mathrm{dm}^{3} \cdot$ tree $^{-1}, 100.0 \mathrm{dm}^{3} \cdot$ tree $^{-1}$ and $97.2 \mathrm{dm}^{3} \cdot$ tree $^{-1}$ respectively, had VOLbelow the mean value of the group $\left(160.6 \mathrm{dm}^{3}\right.$. tree $\left.^{-1}\right)$, showing poor adaptation at Meng-li site.

At Zhao-wang site, significant differences in VOL could be observed among the clones tests (Table 5). B69 and A50 were statistically higher in VOL growth than control clone I-107. B69, with a VOL of 205.0 dm3.tree1, 12.6\% higher than control clone I-107, was the leader in the group. Next to B69 was A50, with a VOL of 199.8 $\mathrm{dm}^{3} \cdot$ tree $^{-1}, 9.7 \%$ higher than control clone I-107. Not statistically different to control clone I-107 were C90 (190.5 dm dmee $\left.^{-1}\right)$, C108 (189.5 dm dm $^{3} \cdot$ tree $\left.^{-1}\right)$, A12 $\left(183.7 \mathrm{dm}^{3}\right.$. tree $\left.^{-1}\right)$, and B85 $\left(182.6 \mathrm{dm}^{3} \cdot\right.$ tree $\left.^{-1}\right)$. All the clones had a VOL above the mean growth of the group tested (149.8 dm dree $\left.^{-1}\right)$. Several clones, C102 (105.7 $\mathrm{dm}^{3}$. tree $\left.^{-1}\right)$, B65 (104.4 dm dree $\left.^{-1}\right)$, A9 $\left(99.3 \mathrm{dm}^{3}\right.$. tree $\left.^{-1}\right)$ and D115 $\left(94.6 \mathrm{dm}^{3}\right.$.tree $\left.{ }^{-1}\right)$, had VOL below the mean value of the group (149.8 $\mathrm{dm}^{3} \cdot$ tree $\left.^{-1}\right)$, showing poor adaptation at Zhao-wang site.

Based on the above analysis, it is reasonable to say that several of the tested clones, common to three sites, are adapted to the region. Among the clones tested at three sites, A50 and B69, all had a VOL growth significantly above control clone I-107.C108, C90, B85, A12 and $\mathrm{C} 103$ were comparable in VOL growth to control clone I-107 at two or three sites. On the contrary, several clones performed poor and were much lower in VOL than the average, e.g. D113 at three sites, D115, A9, C96 and A43 at Meng-li and Zhao-wang sites, A35 at Gaoqiao and Meng-li sites, C102 at Gao-qiao and Zhao-wang sites. Several clones, however, performed differently at three sites, for instance, clone D117 ranked $3^{\text {rd }}$ at Gaoqiao site in VOL growth, but $12^{\text {th }}$ at Meng-li site and $29^{\text {th }}$ at Zhao-wang site, while B63 ranked $4^{\text {th }}$ at Gao-qiao site, $5^{\text {th }}$ at Meng-li site but $16^{\text {th }}$ at Zhao-wang site and D120 ranked $4^{\text {th }}$ at Meng-li site but $17^{\text {th }}$ at Gao-qiao site and $18^{\text {th }}$ at Zhao-wang site. It is beyond the scope of this study to identify the climatic and/or soil conditions that might cause this different response from the clones, and unless further test of these clones to local conditions, they are not recommended for large scale deployment in establishing poplar plantations for raw materials.

\section{Stem traits}

Average values of selected clones for stem traits and branching characteristics, together with control clones, were presented in Table 6. Desirable attributes of stem form were found in B69. With nearly cylindrical, no or minor crookedness and forking stem and high taper value, B69 showed a promising potential for making veneer. Although inferior to B69, A50 was better in stem form thanI-107 and 2025. A50 and B69 had smaller branch size thanI-107 and 2025. Previous study indicated that a tree with acute branch angle and many small branches were desired for poplar ideotypes for short rotation cultures, i.e. pulpwood, while light horizontal branching was desirable for timber production, i.e. sawtimber or veneer (CEulemans et al., 1990). Result showed that B69 is more suitable than other clones to make veneers by considering stem forms and branching habits.

\section{Wood density and dimensional stability}

Specific gravity of A50, B69 and 2025 was significantly higher than that of I-107 (Table 7), implying higher pulp yield of A50, B69 and 2025 than that of I-107. The higher specific gravity of A50, B69 and 2025 might be explained by the higher specific gravity of their parentage. Although some studies showed that the inter-clonal differences in wood density were determined mainly by differences in growth dynamics i.e. inter-individual variations (LIEVENET al., 2007), many other studies indicated that wood density was genetically controlled. KLASNJA et al. (2003) reported a coefficient of heritability of 0.94 for wood density in Populus deltoides clones, and ZHANG et al. (2003) reported that clonal effects on poplar wood density were stronger than growth trait effects. This study complied with the results of most previous studies.

Shrinkage (radial, tangential and volumetric) as well as shape factor ( $\mathrm{T} / \mathrm{R}$, ratio of tangential to radial shrinkage) is important physical property of wood, and a low shrinkage value, indicating a more stable wood property, is desirable. Results showed that differences in both volumetric shrinkage and shape factor (T/R) among clones were significant. B69 was lower in both volumetric shrinkage and shape factor (T/R) than A50, 2025 and I107, showing the wood of B69 was more stable than other clones tested. However, differences in shape factor were more important than those in absolute volumetric shrinkage (Koubaa et al., 1998). Based on that shape factor, B69could be the best clone for sawn wood based products while I-107 is the leastsuited for that purpose. The positive correlation between density and volumetric shrinkage in previous research (LIEVEN et al., 2007) was not observed in this study.

\section{Peeling and plywood property}

Clone 2025 showed most clipping losses in peeling due to its less cylindrical and more crooked stem, and less taper value (Table 8). Clipping losses caused by holes and low taper could be reduced by an adapted tree management such as earlypruning and dense planting. However, clipping losses due to the crack after peeling could not be solved by tree management as the cracks were caused by the release of internal growth stresses which variedclonally (LIEVEN, 2007). There were no significant differences in veneer sheet shrinkage among the clones tested. Only 3 to 5 panels per clone were produced due to the elimination of low quality veneers. Glue bond strength of the 3-layer plywood was presented in Table 8 . For all clones, the board propertieswere well within range to produce plywood for structural application. However, differences among clones could be observed. The average strength values of plywood made of A50, B69 and 2025 were significantly higher than that of I107, indicating I-107 was less desirable for making ply- 
Table 5. - DBH, HT and VOL of 40 hybrid poplar clones grown from 2005 to 2010 at Meng-li, Chang-qing District and at Zhao-wang, Lai-yang City.

\begin{tabular}{|c|c|c|c|c|c|c|c|c|c|c|}
\hline \multicolumn{5}{|c|}{ Meng-li site } & \multicolumn{5}{|c|}{ Zhao-wang sile } & \multirow[b]{2}{*}{$\begin{array}{c}\text { Ranki } \\
\text { ng }\end{array}$} \\
\hline Clone & $\begin{array}{l}\text { DBH } \\
(\mathrm{cm})\end{array}$ & $\begin{array}{l}\mathrm{HT} \\
\text { (m) }\end{array}$ & $\begin{array}{l}\text { Vor." } \\
\left(\mathrm{dm}^{3} \cdot \operatorname{trcc}^{-1}\right)\end{array}$ & $\begin{array}{l}\text { Vol } \\
\text { compared to } \\
\text { I-107(\%) }\end{array}$ & Clone & $\begin{array}{l}\text { DBH } \\
(\mathrm{cm})\end{array}$ & $\begin{array}{l}\text { HT } \\
\text { (m) }\end{array}$ & $\begin{array}{l}\text { VOL." } \\
\left(\mathrm{dm}^{3}, \mathrm{trec}^{-1}\right)\end{array}$ & $\begin{array}{l}\text { VOI } \\
\text { compared to } \\
\text { I- } 107(\%)\end{array}$ & \\
\hline$\wedge 50$ & 19.8 & 19.3 & $236.4^{4}$ & 126.7 & $\mathrm{~B} 69$ & 18.8 & 18.4 & $205.0^{\mathrm{i}}$ & 112.6 & 1 \\
\hline$B 69$ & 19.6 & 19.3 & $233.2^{: b}$ & 125.0 & $\triangle 50$ & 18.9 & 17.9 & $199.8^{a b x}$ & 109.7 & 2 \\
\hline 0.103 & 19.2 & 18.8 & $217.5^{b x}$ & 116.5 & $\cos 0$ & 18.7 & 17.4 & $1901.5^{\mathrm{it}) \mathrm{w}}$ & 104.6 & 3 \\
\hline $\mathrm{D} 120$ & 19.2 & 18.4 & $213.7^{\text {cd }}$ & 114.5 & C 108 & 18.5 & 17.6 & $189.5^{\mathrm{lec}}$ & 104.0 & 4 \\
\hline 1363 & 18.6 & 18.2 & $197.4^{\mathrm{dc}}$ & 105.8 & A12 & 18.4 & 17.3 & $183.7^{\mathrm{cd}}$ & 100.9 & 5 \\
\hline $\mathrm{L} 35$ & 18.3 & 18.7 & $195.6^{d c}$ & 104.8 & 1385 & 18.3 & 17.4 & $182.6^{c d c}$ & 100.3 & 6 \\
\hline $\mathrm{C} 108$ & 18.3 & 18.1 & $190.0^{=f}$ & 101.8 & I- 107 & 18.2 & 17.6 & $182.1^{\text {cde }}$ & 100.0 & 7 \\
\hline I- 107 & 18.3 & 17.7 & $186.6^{\mathrm{tij}}$ & 100.0 & C 103 & 18.2 & 17.2 & $178.8^{c d}$ & 98.2 & 8 \\
\hline $\mathrm{C} 90$ & 18.2 & 17.7 & $183.9^{2+t_{h} h}$ & 98.6 & $\Delta 17$ & 17.9 & 17.0 & $172.4^{\mathrm{del}}$ & 94.7 & 9 \\
\hline$B 85$ & 17.9 & 17.9 & 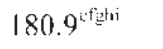 & 96.9 & DI 18 & 17.7 & 17.0 & $168.2^{\cdot 1 \times}$ & 92.4 & 10 \\
\hline A12 & 17.9 & 17.5 & $176.0^{\text {tishij }}$ & 94.3 & L35 & 17.3 & 17.1 & 162.0 & 89.0 & 11 \\
\hline 10117 & 17.6 & 17.5 & 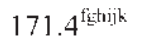 & 91.9 & $B 78$ & 17.3 & 16.9 & 159.1 & 87.4 & 12 \\
\hline Г)118 & 17.7 & 17.3 & $171.0^{\mathrm{gh} i \mathrm{ijk}}$ & 91.6 & $\mathrm{~B} 79$ & 17.1 & 17.0 & 156.9 & 86.1 & 13 \\
\hline$B 78$ & 17.6 & 17.4 & $169.1^{\mathrm{al} h \mathrm{ijk} \mathrm{J}}$ & 90.6 & $\mathrm{~A} 26$ & 17.3 & 16.6 & 156.8 & 86.1 & 14 \\
\hline 2025 & 17.8 & 16.9 & $168.0^{\text {ghijil:1 }}$ & 90.0 & B81 & 17.1 & 16.9 & 156.1 & 85.7 & 15 \\
\hline B881 & 17.5 & 17.2 & 165.7 & 88.8 & $B 63$ & 17.1 & 16.8 & 153.8 & 84.4 & 16 \\
\hline D122 & 17.4 & 17.3 & 164.4 & 88.1 & I- 69 & 17.0 & 16.9 & 153.1 & 84.1 & 17 \\
\hline $\mathrm{\Gamma} 379$ & 17.5 & 17.0 & 164.3 & 88.0 & ГD120 & 17.1 & 16.5 & 151.8 & 83.4 & 18 \\
\hline Al8 & 17.4 & 17.2 & 164.0 & 87.9 & $\mathrm{~B} 72$ & 16.8 & 16.7 & 151.5 & 83.2 & 19 \\
\hline $\mathrm{C} 102$ & 17.2 & 17.1 & 159.3 & 85.4 & $\wedge 8$ & 17.0 & 16.0 & 151.0 & 82.9 & 20 \\
\hline$B 72$ & 17.2 & 17.1 & 158.6 & 85.0 & $A 35$ & 16.9 & 16.8 & 150.1 & 82.4 & 21 \\
\hline $\mathrm{I}-69$ & 17.1 & 17.2 & 157.9 & 84.6 & $\wedge 49$ & 17.0 & 16.4 & 149.7 & 82.2 & 22 \\
\hline 1)110 & 17.2 & 16.9 & 157.4 & 84.4 & Al6 & 16.9 & 16.2 & 146.2 & 80.3 & 23 \\
\hline A8 & 17.2 & 16.8 & 156.1 & 83.7 & $\mathrm{~B} 83$ & 16.9 & 16.3 & 145.9 & 80.1 & 24 \\
\hline$\Gamma 383$ & 16.9 & 17.2 & 154.0 & 82.5 & 2025 & 16.9 & 16.1 & 144.2 & 79.2 & 25 \\
\hline B74 & 17.0 & 16.9 & 153.4 & 82.2 & D123 & 16.7 & 16.4 & 143.7 & 78.9 & 26 \\
\hline $\mathrm{T} 365$ & 16.9 & 16.9 & 152.1 & 81.5 & $\Lambda 51$ & 16.8 & 16.2 & 143.3 & 78.7 & 27 \\
\hline D) 23 & 16.7 & 16.9 & 148.9 & 79.8 & D1 22 & 16.5 & 16.1 & 138.8 & 76.2 & 28 \\
\hline A49 & 16.5 & 16.9 & 145.0 & 77.7 & [)117 & 16.5 & 16.1 & 137.1 & 75.3 & 29 \\
\hline$\wedge 21$ & 16.8 & 16.2 & 144.1 & 77.2 & D) 13 & 16.3 & 16.2 & 134.9 & 74.1 & 30 \\
\hline A17 & 16.5 & 16.4 & 140.7 & 75.4 & $\wedge 21$ & 16.4 & 16.2 & 134.6 & 73.9 & 31 \\
\hline A51 & 16.4 & 16.6 & 140.6 & 75.3 & Al 8 & 16.1 & 16.0 & 130.0 & 71.4 & 32 \\
\hline$\wedge 16$ & 16.2 & 16.5 & 136.1 & 72.9 & Г)1 10 & 16.0 & 15.9 & 127.6 & 70.1 & 33 \\
\hline$\wedge 43$ & 15.8 & 15.8 & 124.7 & 66.8 & $C 96$ & 15.9 & 15.5 & 123.4 & 67.8 & 34 \\
\hline DI13 & 15.5 & 15.7 & 118.9 & 63.7 & B74 & 15.7 & 15.7 & 122.1 & 67.1 & 35 \\
\hline$C 96$ & 15.4 & 15.2 & 113.1 & 60.6 & 143 & 15.4 & 15.0 & 112.3 & 61.7 & 36 \\
\hline$\Lambda 26$ & 15.2 & 15.4 & 111.5 & 59.8 & 0.102 & 15.1 & 14.8 & 105.7 & 58.1 & 37 \\
\hline A35 & 15.0 & 14.9 & 104,6 & 56.0 & B 65 & 15.0 & 14.7 & 104.4 & 57.3 & 38 \\
\hline $\mathrm{A} 9$ & 14.7 & 14.7 & 100.0 & 53.6 & A9 & 14.7 & 14.5 & 99.3 & 54.5 & 39 \\
\hline D1 I 5 & 14.6 & 14.5 & 97.2 & 52.1 & D1 15 & 14.6 & 14.2 & 94.6 & 52.0 & 40 \\
\hline Mcan & 17.2 & 17.0 & 160.6 & & & 16.9 & 16.4 & 149.8 & & \\
\hline $\mathrm{P}$ & $<10^{-3^{2}}$ & $<10^{-3}$ & $<10^{-3}$ & & & $<10^{-3}$ & $<10^{-5}$ & $<10^{-5}$ & & \\
\hline $\mathrm{CV}(\%)$ & 2.7 & 2.4 & 7.2 & & & 2.3 & 2.6 & 6.1 & & \\
\hline $\mathrm{LSD}_{\mathrm{fo}}$ & 0.8 & 0.7 & 18.7 & & & 0.6 & 0.7 & 14.8 & & \\
\hline
\end{tabular}

* Only clones with VOLs statistically higher than or equal to control clone I-107 are labeled. 
Table 6. - Average values for stem traits of selected clones.

\begin{tabular}{|c|c|c|c|c|c|c|}
\hline \multirow{2}{*}{ Clone } & \multicolumn{4}{|c|}{ Score } & \multirow{2}{*}{$\begin{array}{l}\text { Branching } \\
\left({ }^{\circ}\right)\end{array}$} & \multirow{2}{*}{ Taper } \\
\hline & Roundness & Crookedness & l:orking & Branch diameter & & \\
\hline $\mathrm{A} 50$ & 0.21 & 0.78 & 0.23 & 0.62 & 80 & 95 \\
\hline B69 & 0.13 & 0.60 & 0.05 & 0.73 & 58 & 102 \\
\hline $1-107$ & 0.35 & 0.82 & 0.30 & 0.21 & 57 & 95 \\
\hline 2025 & 0.42 & 1,16 & 0.45 & 1.81 & 62 & 91 \\
\hline
\end{tabular}

The scoring scheme for each trait is given under Material and Methods.

Table 7. - Volume weighted average specific gravity, shrinkage values (radial $[R]$, tangential $[\mathrm{T}]$ and volumetric) and shape factor (T/R) of selected clones.

\begin{tabular}{llllll}
\hline Clone & A50 & $\mathrm{B} 69$ & $\mathrm{I}-107$ & 2025 & Ranking \\
Specific gravity $\left(\mathrm{g} \cdot \mathrm{cm}^{-3}\right)$ & 0.39 & 0.37 & 0.33 & 0.37 & aaba \\
Radial shrinkage $(\%)$ & 0.15 & 0.13 & 0.09 & 0.14 & aaba \\
Tangential shrinkage $(\%)$ & 0.18 & 0.13 & 0.13 & 0.16 & abba \\
Shape factor $(\mathrm{T} / \mathrm{R})$ & 1.2 & 1.0 & 1.4 & 1.2 & bcab \\
Volumetric shrinkage $(\%)$ & 0.29 & 0.21 & 0.26 & 0.25 & abaa \\
\hline
\end{tabular}

Table 8. - Losses, shrinkage of veneers and quality of 3-layer-plywood.

\begin{tabular}{llllll}
\hline & A50 & B69 & $1-107$ & 2025 & Ranking \\
\hline Loss by clipping (\%) & 5.0 & 4.0 & 4.0 & 6.0 & beca \\
Shrinkage of veneer (\%) & 14.9 & 14.5 & 14.4 & 15.0 & ns \\
Glue bond strength (MPa) & 0.852 & 0.867 & 0.753 & 0.842 & aaba \\
\hline
\end{tabular}

ns: not significant at 0.05 level.

Table 9. - Fiber morphology and chemical composition of clones selected.

\begin{tabular}{|c|c|c|c|c|c|c|c|}
\hline Clone & $\begin{array}{l}\text { riber } \\
\text { (mm) }\end{array}$ & lengh & $\begin{array}{l}\text { Aspect } \\
\text { ratio }\end{array}$ & $\begin{array}{l}\text { Holocellulose } \\
(\%)\end{array}$ & $\begin{array}{l}\text { Cellulose } \\
(\%)\end{array}$ & $\begin{array}{l}\text { Klason } \\
\text { lignin }(\%)\end{array}$ & $\begin{array}{l}\text { E1-OH-Benzene } \\
\text { extractive }(\%)\end{array}$ \\
\hline$\Lambda 50$ & 1.05 & & 45.4 & 81.5 & 50.3 & 17.46 & 1.94 \\
\hline B69 & 1.06 & & 45.0 & 82.6 & 50.5 & 17.02 & 1.52 \\
\hline I- 107 & 1.07 & & 45.7 & 81.1 & 50.3 & 17.23 & 1.45 \\
\hline 2025 & 1.00 & & 43.3 & 81.4 & 49.3 & 18.61 & 1.59 \\
\hline Ranking & 115 & & aacb & ns & 115 & aaab & abbb \\
\hline
\end{tabular}

Ns: not significant at 0.05 level.

wood than A50, B69, and 2025 in case of glue bond strength. However, plywood strength could be enhanced by accurate layering structure of veneer sheets.

Based on the shape factor, dimensional stability, peeling property and plywood strength, it is reasonable to conclude that B69 is better in making veneer and plywood than other clones tested.

\section{Fiber morphology and chemical composition of clones selected}

Fiber morphology is closely related with the pulping property and longer fiber and higher aspect ratio (more than 30$)$ result in good pulp strength properties. ZOBEL et al. (1995) reported that for fiber length, a genetic control had been demonstrated. Other research has shown that selection of a fast growing hybrid does not affect the fiber length and growth rate of short-rotation poplar can be increased without concern that fiber length may be negatively affected (DEBELL et al., 1998). Consistent with previous studies, test results showed that fiber length was not decreased with the fast growing rate. All the clones tested had fiber lengths with more than $1 \mathrm{~mm}$ and aspect ratio more than 43 , classifying the four clones tested in medium level pulpwood (fiber length between $0.9-1.6 \mathrm{~mm}$ ). It was believed that higher holo- 
Table 10. - Pulp yield and hand sheet properties of poplar clones selected.

\begin{tabular}{|c|c|c|c|c|c|c|c|c|c|}
\hline Clone & $\begin{array}{l}\text { Pulp } \\
\text { yicld } \\
(\%)\end{array}$ & $\begin{array}{l}\text { Bcating } \\
\text { degree } \\
\left({ }_{S R}\right)\end{array}$ & $\begin{array}{l}\text { Opacily } \\
(\%)\end{array}$ & $\begin{array}{l}\text { Brightness } \\
(\% \text { ISO })\end{array}$ & $\begin{array}{l}\text { Bulk } \\
\left(\mathrm{cm}^{3} \cdot \mathrm{g}^{-1}\right)\end{array}$ & $\begin{array}{l}\text { Brealing } \\
\text { length } \\
(\mathrm{km})\end{array}$ & $\begin{array}{l}\text { Tensile } \\
\text { index } \\
\left(\mathrm{Nm}, \mathrm{g}^{-1}\right)\end{array}$ & $\begin{array}{l}\text { Tear index } \\
\left(\mathrm{mN} \cdot \mathrm{m}^{2} \cdot \mathrm{y}^{-1}\right)\end{array}$ & $\begin{array}{l}\text { Burst index } \\
\left(\mathrm{k} P \mathrm{u}^{\mathrm{n}} \mathrm{In}^{2} \cdot \mathrm{g}^{-1}\right)\end{array}$ \\
\hline A50 & 87.6 & 46.0 & 79.3 & 79.8 & 2.33 & 3.40 & 33.35 & 4.25 & 1.98 \\
\hline$B 69$ & 86.2 & 48.0 & 79.2 & 77.5 & 2.22 & 3.28 & 32.18 & 3.15 & 1.71 \\
\hline$[-107$ & 82.5 & 46.0 & 80.9 & 79.7 & 2.33 & 3.53 & 34.61 & 3.82 & 1.66 \\
\hline 2025 & 85.6 & 46.0 & 80.5 & 79.2 & 2.33 & 3.22 & 31.59 & 3.04 & 1.70 \\
\hline
\end{tabular}

cellulose/cellulose and lower lignin contents could result in higher pulp yield. There were no significant differences in cellulose and holocellulose contents among the clones tested. Except for 2025, other clones i.e. A50, B69 and I-107 had lignin contents less than 18\% (Table 9).

\section{Pulp properties from APMP process}

APMP process is demonstrated to be a better process than others in terms of overall pulp property development, process consumption, yield and other process costs. Poplar woods, with their low wood density and high brightness make them particularly suited for alkali treated process such as APMP. Results showed that under the process conditions mentioned in materials and methods, all the clones tested had a pulp yield of more than $82 \%$; brightness of more than $77.5 \%$ ISO (with A50 more than 79.8\% ISO); breaking length more than $3.00 \mathrm{~km}$; tear index more than $3.0 \mathrm{mN} . \mathrm{m}^{2} . \mathrm{g}^{-1}$; and burst index more than $1.60 \mathrm{kPa} \cdot \mathrm{m}^{2} \cdot \mathrm{g}^{-1}$ (Table 10). They were comparable to other low density hardwood species, e.g. Populus tremuloides and Eucalyptus urophylla (YANG, 2006). Among the clones tested, A50 was superior in pulp yield, brightness, and strength properties (in case of tear index and burst index) than other clones. B69 was inferior in brightness, bulk, and strength properties than other clones. However, it was comparable to other clones in pulp yield.

Based on the results on the fiber morphology, chemical composition and APMP pulp properties, it is reasonable to conclude that all the clones tested can be used for pulpwood. Clone 50, superior in pulp yield, brightness, and strength properties, is more suitable for pulpwood than other clones tested.

\section{Conclusion}

Significant variation in growth rate among backcrossedprogenies from controlled pollination within theAigeiros Section can be observed, which makes the selection of fast-growing hybrid poplar clones possible. Among the clones tested, A50 and B69, two hybrid poplar clones from cross combinations of I-72 $\times$ PE-3-71 andI-69 $\times$ PE-3-71 respectively, had higher growth rates and adaptation thancontrol clone I-107 at the age of 6 years at Meng-li site and Zhao-wang site, and 10 years at Gao-qiao site, showing a promising potential in establishing poplar plantation in the region. It can be con- cluded that A50 has desirable characteristics supporting its application in pulp industry while B69 is more suitable for veneer and plywood due to its less clipping losses resulted from roundness, straight and higher taper stem, and the less dimensional shrinkage. In 2010, the selected clones A50 and B69 were officially admitted to national poplar cultivar (clone) list and were permitted to extend in regions with climatic and soil conditions similar to Shandong.

Early selection is useful in tree breeding. However, results with a smaller probability of error can only be achieved after a long period of research (REDEI, 2000). As the conclusion is based only on the early performance of clones tested, further research on clonal variation in growth performance as well as wood properties through time e.g. 10-15 year are needed.

\section{Acknowledgements}

This research was funded by Shandong Department of Science \& Technology as a project 'Breeding of fastgrowing poplar clones for industrial use'. We thank XU XING-HUA, Li CHANG-CHUN and SuI RI-GUANG for maintaining the trial sites and WANG WEI-DONG, WANG YUEHAI, Xu Shou-Hua and Dong YU-FEng for their assistance in the lab, greenhouse and field, and WANG QIANG for editing the artwork. Special thanks goes to the anonymous reviewer for his/her valuable comments which are helpful in revising and improving the paper.

\section{References}

ADRIAN, A. (2002): Changes through time in traits of poplar clones in selection trials. New For. 23: 109-111.

Ceulemans, R., R. F. Stettler, T. M. Hinckely, J. G. IsEBRANDS and P. E. HeIlman (1990): Crown architecture of Populus clones as determined by branch orientation and branch characteristics. Tree Physiol. 7: 157-167.

DeBell, J. D., B. L. Gartner and D. S. DeBell (1998): Fiber length in young hybrid Populus stems grown at extremely different rates. Can. J. For. Res. 28: 603-608.

FAO (1980): Poplars and willows in wood production and land use. FAO, Rome.

Foster, G. S. (1988): Provenance variation of eastern cottonwood in the Lower Mississippi Valley. Silvae Genetica 35: 32-38.

Heilman, P. E. (1999): Planted forests: poplars. New For. 17: 89-93. 